\title{
Potential Markets for Snacks: A Role for New Zealand Snack Products ${ }^{\dagger}$
}

\author{
M. Yan ${ }^{1,2}$, E. Rush ${ }^{2}$ and S. Shaikh ${ }^{1}$ \\ 1 Health and Community Network, Unitec Institute of Technology, Auckland 1025, New Zealand; \\ myan@unitec.ac.nz (M.Y.); sshaikh@unitec.ac.nz (S.S.) \\ 2 AUT Food Network, Auckland University of Technology, Auckland 1010, New Zealand; \\ elaine.rush@aut.ac.nz \\ * Correspondence: myan@unitec.ac.nz \\ + Presented at the 2018 Nutrition Society of New Zealand Annual Conference, Auckland, New Zealand, \\ 28-30 November 2018.
}

Published: 13 March 2019

Background: Worldwide there is an increase in the consumption of snack foods and this is a key business driver for the food industry. Snacking impacts on the overall quality of dietary patterns, nutrition and health. In particular, unhealthy snacking is implicated in increasing body weight status and obesity. Consumers' snacking habits have shifted from simply enjoyable towards natural and nutritious for a healthier lifestyle. What is the solution? How to balance?

Methods: In this context, literature on consumer perceptions and health impacts of snacking was explored. Further, information on the latest innovations in snacking, the features of new product launches, and global food and drink consumption trends were sourced from Mintel's reports.

Results: In response to the growing demand of wellness-minded consumers, the food industry has dramatically changed products including sustainable sources of wholesome ingredients to the ways products are packaged, branded and marketed. 'Power to the plants' has become a global food and drink trend. A steady increase between 2016 and 2017 was recorded in the use of food-related claims e.g., 'natural product and ingredients' (29\%) and 'ethical and environmental' (22\%) on global food and drink product launches.

Conclusion: While the potential for new snack products remains high, snack products need new concepts, new ingredients and new messages to stand out. New Zealand has developed an international reputation in food safety and quality related to the natural environment. Snack food development using local ingredients such as oats, flaxseed, fruit and honey would add value for domestic consumers and export markets. While the health star ratings (a scale of $0.5-5$ ) on packaged food help consumers to make healthier choices, there is a need for equal consideration of consumer wants versus needs while developing healthier snacks with verifiable health-related claims, so such an approach could be translated into changes in the food supply to support healthier eating habits.

Supplementary Material: The poster is available online at www.mdpi.com/2504-3900/8/1/46/s1.

(C) 2019 by the authors. Licensee MDPI, Basel, Switzerland. This article is an open access article distributed under the terms and conditions of the Creative Commons Attribution (CC BY) license (http://creativecommons.org/licenses/by/4.0/). 